\title{
Optimization of an Externally Mixed Biogas Plant Using a Robust CFD Method
}

\author{
Jonas Müller ${ }^{\mathrm{a}, *}$, Christina Schenk ${ }^{\text {«, }, \mathrm{b}, * \text {, Rainer Keicher }}{ }^{\mathrm{a}}$, Dominik Schmidtt ${ }^{\mathrm{a}}$, Volker Schulz ${ }^{\mathrm{c}}$, Kai Velten $^{\mathrm{a}}$ \\ ${ }^{a}$ Hochschule Geisenheim University, Department of Modeling and Systems Analysis, 65366 Geisenheim, Germany \\ ${ }^{b}$ Carnegie Mellon University, Department of Chemical Engineering, Pittsburgh, PA 15213, USA \\ ${ }^{c}$ Trier University, Department of Mathematics, 54286 Trier, Germany
}

\begin{abstract}
Renewable energy sources are crucial to react to the continuous increase of energy consumption and pollution by carbon dioxide emissions worldwide. Exemplary electric power can be generated from the production of biogas. There exists a significant demand for improvement in terms of ecological stability and economic profitability for the biogas production process. Biogas plants have to be continuously or periodically mixed to ensure the homogenization of fermenting and freshly fed substrate. Mixers installed at the exterior of the biogas plant provide easier access during maintenance and repairs than submerged mixers but concerns of sufficient mixing deter many operators from using this technology. Recent studies have focused on different mixer types, the underlying model, the shape of the mixer and also the optimization of geometry parameters. However, most investigations have been made for small-scale reactors and due to the increased amount of dynamic fluid behavior, results can not be scaled up easily. In this paper, a new solution for improved homogenization of the substrate mixture by proposing optimal mixer configurations with steady flow with respect to a wide range of viscosity properties for a large-scale reactor is provided. Robust optimization of a biogas reactor is coupled with $\mathrm{CFD}^{1}$ simulations to improve parameters for the angles of inflow and the position of the substrate outlet. The optimization objective is to minimize the area in the tank which is poorly mixed, e.g. where the velocity magnitude during mixing falls below a certain threshold. Different dry substance contents are being investigated to account for the varying rheological properties of different substrate compositions. Therefore a robust optimization approach with regard to the rheology is studied. Two different dry substance content distributions are considered. The velocity threshold is calculated for each dry substance content from the mixer-tank configuration of a real biogas reactor in Brandenburg, Germany (BGA Warsow GmbH \& Co.KG). The optimization results are compared to simulations of this original configuration and to optimization results for each dry substance content individually. The significance of this approach to improve mixing is elucidated. The optimized configurations reduce the dead volume zones significantly compared to the original configuration. The outcomes of this paper can be particularly useful for plant manufacturers and operators for optimal mixer placement and configuration in large tanks.
\end{abstract}

\footnotetext{
(2) Corresponding author

${ }^{*}$ Co-first authors

Email addresses: jonas.mueller@hs-gm.de (Jonas Müller), schenk@cmu.edu (Christina Schenk ${ }^{\text {th }}$, ), rainer.keicher@hs-gm.de (Rainer Keicher), dominik.schmidt@hs-gm.de (Dominik Schmidt), volker.schulz@uni-trier.de (Volker Schulz), kai.velten@hs-gm.de (Kai Velten)
} 


\begin{tabular}{|c|c|c|c|}
\hline \multicolumn{4}{|l|}{ Nomenclature } \\
\hline Acronyms & & $\tau_{i j}$ & shear stress, $\mathrm{Pa}$ \\
\hline$C F D$ & $\begin{array}{l}\text { Computational Fluid Dynam- } \\
\text { ics }\end{array}$ & $\tau_{i j}^{F}$ & $\begin{array}{l}\text { Favre-averaged turbulent stress, } \\
\mathrm{Pa}\end{array}$ \\
\hline (L)GPL & (Lesser) General Public License & $\tilde{P}_{k}$ & production limiter \\
\hline $\mathrm{CAD}$ & Computer Aided Design & $\varepsilon$ & velocity threshold, $\mathrm{m} \mathrm{s}^{-1}$ \\
\hline DAKOTA & $\begin{array}{l}\text { Design Analysis Kit for Opti- } \\
\text { mization and Terascale Applica- } \\
\text { tions }\end{array}$ & $\begin{array}{l}\zeta \\
d\end{array}$ & $\begin{array}{l}\text { vector of weighting factors } \\
\text { vector of dead volumes, } \mathrm{m}^{3}\end{array}$ \\
\hline DIRECT & DIviding RECTangles & $P_{k}$ & production measure \\
\hline DSC & Dry Substance Content & $r_{i n}$ & inlet radius, $\mathrm{m}$ \\
\hline FOAM & $\begin{array}{l}\text { Field Operation And Manipu- } \\
\text { lation }\end{array}$ & $\begin{array}{l}S \\
U_{\text {in }}\end{array}$ & $\begin{array}{l}\text { invariant measure of strain rate } \\
\text { velocity at inlet, } \mathrm{ms}^{-1}\end{array}$ \\
\hline RCENOBIO & $\begin{array}{l}\text { Robust energy-optimization of } \\
\text { fermentation processes for the } \\
\text { production of biogas and wine }\end{array}$ & $\begin{array}{l}U_{m a g} \\
y\end{array}$ & $\begin{array}{l}\text { magnitude velocity, } \mathrm{m} \mathrm{s}^{-1} \\
\text { distance to nearest wall, } \mathrm{m}\end{array}$ \\
\hline $\mathrm{SST}$ & Shear Stress Transport & $K$ & consistency coefficient, $\mathrm{Pa} / \mathrm{s}^{\mathrm{n}}$ \\
\hline Parameters & & $n$ & Power Law index \\
\hline$\beta, C D_{k \omega}, \sigma_{k}, \sigma_{\omega}$ & $\begin{array}{l}\text { parameters from combination } \\
\text { of } k-\epsilon \text { and } k-\omega \text { model }\end{array}$ & $\begin{array}{l}\text { Variables } \\
\epsilon, \omega\end{array}$ & \\
\hline$\beta^{\star}$ & model constant & & kinetic energy, $\mathrm{m}^{2} \mathrm{~s}^{-3}$ \\
\hline$\dot{\gamma}$ & shear rate, $\mathrm{s}^{-1}$ & $u_{i}, u_{j}$ & velocity components, $\mathrm{ms}^{-1}$ \\
\hline$\dot{V}$ & volumetric fow rate, $\mathrm{m}^{3} \mathrm{~s}^{-1}$ & $\theta$ & vector of design variables, ${ }^{\circ}$ \\
\hline$\eta$ & viscosity, $\mathrm{Pas}$ & $k$ & turbulent kinetic energy, $\mathrm{m}^{2} \mathrm{~s}^{-2}$ \\
\hline$\eta_{L}$ & laminar viscosity, $\mathrm{Pas}$ & $p$ & pressure, $\mathrm{Pa}$ \\
\hline$\eta_{T}$ & turbulent viscosity, Pas & $U$ & velocity, $\mathrm{m} \mathrm{s}^{-1}$ \\
\hline$\rho$ & fluid density, $\mathrm{kg} \mathrm{m}^{-3}$ & $x_{i}, x_{j}$ & coordinate direction \\
\hline
\end{tabular}

Keywords: Anaerobic Digestion, Bioenergy, CFD-Simulation, OpenFOAM, Robust Optimization

\section{Introduction}

\footnotetext{
${ }^{1}$ CFD: Computational Fluid Dynamics

${ }^{2}$ (L)GPL: (Lesser) General Public License

${ }^{3}$ CAD: Computer Aided Design

${ }^{4}$ DAKOTA: Design Analysis Kit for Optimization and Terascale Applications

${ }^{5}$ DIRECT: DIviding RECTangles

${ }^{6}$ DSC: Dry Substance Content

${ }^{7}$ FOAM: Field Operation and Manipulation

${ }^{8}$ RCENOBIO: Robust Energy-Optimization of Fermentation Processes for the Production of Biogas and Wine

${ }^{9} \mathrm{SST}$ : Shear Stress Transport
} 
Introduction. The year 2014 particularly showed the effect of the increasing use of renewable energy sources to react to the continuous increase of energy consumption and pollution by carbon dioxide emissions worldwide. Despite the power rise by $8.5 \%$ or 135 Gigawatt and the continuously increasing energy consumption, it was possible to hold the carbon dioxide emissions at a constant level (Sawin et al., 2015). Exemplary electric power generated from biogas is an essential part of the energy mix in Germany accounting for $32370 \mathrm{GW}$ h or $5.4 \%$ of gross electricity consumption in 2016 (Umweltbundesamt, 2017). That is why the production of biogas is important for many countries. In some countries it is already common practice and in others it is planned to be introduced or expanded (Kemausuor et al., 2018). However, from 2020 due to many legal and economic regulations in Germany, a realignment of the biogas production becomes unavoidable (Theuerl et al., 2019). Theuerl et al. (2019) provide a vision of the future agricultural biogas plant. The investigations made in the present paper provide a small step towards the accomplishment of their envisioned goals.

Since biogas reactors rely on a continuous, fermentative process, they have to be constantly fed with new substrate. To make the production of biogas more efficient regarding ecological stability and economic profitability, the fermentation process has to be optimized. Natural mixing through bubble formation and convection are not sufficient in anaerobic digesters because of the high substrate viscosity (Vesvikar and Al-Dahhan, 2005). Mechanical mixing therefore plays an important role in providing contact of the active biomass with the fresh substrate, distributing fresh feed uniformly in the whole tank, avoiding builtup of toxic substances, and preventing temperature gradients and substrate layering inside the tank (Weiland, 2010). One common type of mixing is through an external draft tube allowing the operator to maintain and repair the high speed impeller mixer without emptying the tank. A major disadvantage of this type of anaerobic digester is the fact, that once installed, the configuration can not easily be changed. Therefore an optimal mixer placement has to be determined before constructing the plant.

Over the last decade a number of authors have applied $\mathrm{CFD}^{1}$ techniques to investigate different aspects of anaerobic reactors (for an overview see Sadino-Riquelme et al. (2018)). While some authors have focused on different mixer types (Meroney and Sheker, 2014, Alok and Immanuel, 2014), others have studied the influence of the modeling approach (Aubin et al., 2004), the impact of switching between nozzle series during the process (Dapelo and Bridgeman, 2018) or have investigated the rheological behavior of biogas substrates (Um and Hanley, 2008). However, most work has been done on small-scale reactors and results can not be scaled up easily because of much more dynamic fluid behavior.

Ansoni and Seleghim (2016) describe a multiobjective optimization method based on a posteriori performance parameters calculated from $\mathrm{CFD}^{1}$ flow solutions optimizing certain geometry parameters. However, this work is also focused on a small-scale reactor.

Most other works pursue the aim of optimizing the shape of the mixer (Donno et al., 2019, Guo et al., 2015, Pasquale et al., 2013), whereas the approach underlying the study in this paper focuses on the optimization of the mixer configurations with steady flow and with respect to a wide range of viscosity properties. More details of the 
current study can be found in Müller (2019).

In the current study, the steady-state flow of the biogas substrate inside the tank driven by an external mixer is simulated. In order to make the flowfield more homogeneous, an optimization framework is wrapped around the $\mathrm{CFD}^{1}$ simulation. In this context, the primary focus of this research is to minimize the formation of so called dead volume zones. The horizontal and vertical inflow angle as well as the outlet position of the external draft tube are left as degrees of freedom in the optimization process. In practice the formation of dead volume zones brings along a huge risk. For example, if a dead volume zone forms in the shape of a column in the middle of the tank that means that the compound and $\mathrm{pH}$-value in this zone will change over time compared to the well-mixed parts closer to the tank walls. Consequently, the breakdown of this pile can lead to a collapse of the ecosystem. Thus a very costly draining of the fermenter is required followed by a slow restart over a few weeks time.

The objective value in the optimization framework, the dead volume zone, is calculated by taking a theoretic velocity threshold as the measure that divides the tank into two parts- a slow moving zone or dead volume zone and a fast moving zone. Within the scope of this study it is not possible to take the goodness of mixture as the objective quantity, as suggested by Kraume (2013), because the matter of the materials can not be investigated individually. Neither does considering the velocity gradient as the decisive objective measure seem to be ideal within this work. According to the plant operator the disposition of the substrate in one place can cause problems even if it is well-mixed within the slow moving zone. Moreover, a slow absolute velocity can be considered as the critical measure of mixture quality here because chemical reactions in the interior of the slow moving zone, especially during acidogenesis, lower the $\mathrm{pH}$ value resulting in a change of the bacterial flora's composition (for more on the subprocesses of biogas production see e.g. Gujer and Zehnder (1983)). This in return can lead to a collapse of the ecosystem in the whole fermenter.

To respect the dependence on the rheological properties of the compound, the dry substance content is taken into account as an uncertainty and a robust optimization approach is performed using gradient-free optimization, i.e. here using the DIRECT ${ }^{5}$ algorithm. The robust optimization results are compared to single-set optimization results for each examined dry substance content and to values resulting from taking the geometrical properties into account as they are actually installed in the modeled biogas plant.

In Section 2 the materials and methods behind this robust $\mathrm{CFD}^{1}$ optimization are described. The $\mathrm{CFD}^{1}$ model, the methodology for the $\mathrm{CFD}^{1}$ simulation, the software framework and the robust optimization approach including the formulation of the objective based on the velocity threshold calculated from the original configuration are introduced. In Section 3 the introduced materials and methods are applied and visualized by some numerical results. It follows a comparison and discussion of the simulation results of the original configuration with results from the individual single-set optimizations (for each dry substance content independently) and the robust optimization for two different distributions of the uncertainty set. Conclusions are presented in Section 4. 


\section{Materials and Methods}

\subsection{Biogas Power Plant}

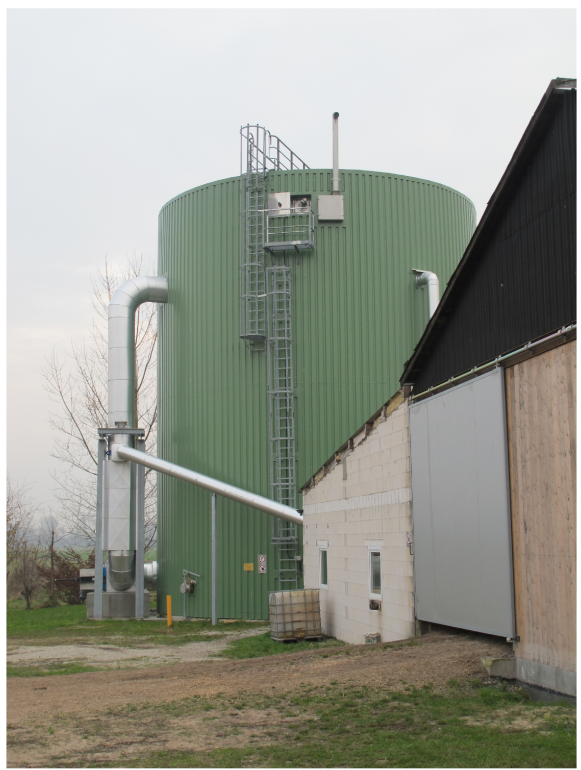

Figure 1: Main fermenter of the biogas plant in Warsow (Germany) with external draft tube and feeding tube for the fresh substrate
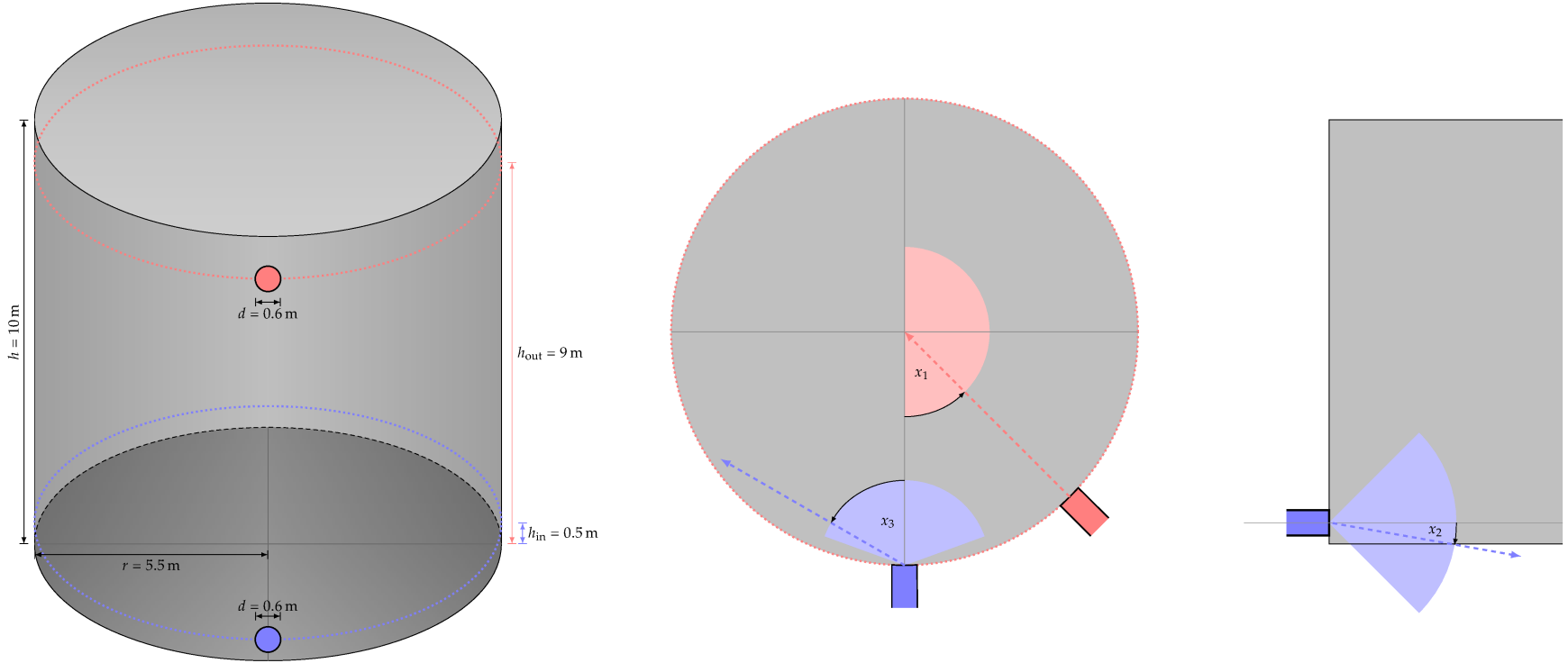

Figure 2: Tank geometry and optimization parameters of the biogas plant in Warsow, Germany

The biogas power plant on which the simulations are based on, is located in Warsow, Brandenburg, Germany (BGA Warsow GmbH \& Co. KG). The plant consists of a main fermenter with a volume of $950 \mathrm{~m}^{3}$ (see Fig. 1 and Fig. 2), a secondary fermenter $\left(600 \mathrm{~m}^{3}\right)$ and a final storage $\left(1000 \mathrm{~m}^{3}\right)$. The secondary fermenter and final storage are connected behind the main fermenter. All of them are hermetically sealed, such that the final storage serves as a second secondary fermenter as well. Figure 1 shows the main fermenter which was originally built as a corn silo and afterwards changed for the usage as a biogas fermenter. The plant is fed daily with approximately $30 \mathrm{t}$ of raw 
material (40\% corn silage, $30 \%$ grass silage, $30 \%$ cow dung and $2-4 \mathrm{t}$ of cow manure). The operating temperature is kept consistently at $43^{\circ} \mathrm{C}$ and the gas yield averages approximately $330 \mathrm{~N} \mathrm{~m}^{3} \mathrm{~h}^{-1}$. Special characteristics of the biogas plant are a shredding process of the biomass before feeding it to the system by means of a twin-screw extruder manufactured by Börner and Börner (2011) and the externally installed axial mixer manufactured by Stirl (2008). The extrusion process guarantees a higher gas yield through an improved homogeneity of the biomass and allows, as a consequence, the mathematical modeling of the tank content as a single phase. The external mixer allows for maintenance procedures and repairs of the mixer without emptying the plant. The fresh substrate is slowly fed via the twin-screw extruder through a feeding tube to the draft tube every two hours during mixing times (for $40 \mathrm{~min}$ during each feeding cycle). The volumetric flow rate is approximately $1.75 \mathrm{~m}^{3} \mathrm{~s}^{-1}$ through the outside piping of the biogas plant at hand .

\subsection{Software, Solver and Turbulence Model}

For 3D-modeling of the biogas plant the $\mathrm{CAD}^{3}$ software SALOME (LGPL ${ }^{2}$ license LGPLv2.1, Version 7.6.0) (Ribes and Caremoli, 2007) is used. The geometry of the fermenter including all relevant in- and outlets for the substrate is modeled using measurements from the manufacturer and plant operator. By processing the modeling data with a Python script using SALOME, it is subsequently possible to perform a design optimization on the geometry by connecting it to the DAKOTA ${ }^{4}$ toolkit as described below. OpenFOAM ${ }^{7}$ is an open source software library written in $\mathrm{C++}$, containing many $\mathrm{CFD}^{1}$ solvers and utilities (Weller et al., 1998). All following computations and analyses are performed using OpenFOAM ${ }^{7}$ Version 2.4.0 (GPL ${ }^{2}$ license GPLv3). Various OpenFOAM ${ }^{7}$ utilities are used to draw up the simulations (e.g. mesh generation, parallelization) and to process the results (e.g. visualization of data, sampling of results, calculation of field numbers). The OpenFOAM ${ }^{7}$ standard solvers use the finite volume method, which is based on the discretization of the governing equations.

The solver which is used here, simpleFOAM ${ }^{7}$, discretizes and solves the underlying momentum, continuity, and energy equations (Navier-Stokes-Equations) up to a stationary convergence of pressure $p$ and velocity $U$ in each cell. The convergence criteria are determined by the user (e.g. residuals $1 \times 10^{-5}$ for $p$ and $U$ ). As a turbulence model the $k-\omega \mathrm{SST}^{2.4}$ model is used, such that the required transport equations are also solved for turbulent kinetic energy $(k)$ and the dissipation rate of turbulent kinetic energy $(\epsilon)$ up to a predetermined convergence tolerance of the residuals $\left(1 \times 10^{-5}\right)$ in each cell. Due to earlier observations of slow moving zones occuring near the tank wall, the $k$ - $\omega$ SST model seemed to be the ideal choice here as it provides a particularly robust and accurate near wall treatment (Menter et al., 2003). Relaxation factors were set to 0.3 and 0.7 for $p$ and for $U, k$, and $\epsilon$, respectively.

To conduct the following optimization studies, the $\mathrm{CFD}^{1}$ software is coupled with the DAKOTA ${ }^{4}$ toolkit $\left(\mathrm{LGPL}^{2}\right.$ license LGPLv3, Version 6.2) by Sandia Corporation (Adams et al., 2014). This software acts as a black box optimization solver where the black box is the OpenFOAM ${ }^{7}$ model. 


\subsection{Flow Model Development}

The biogas substrate flow inside the tank is modeled by the incompressible Navier-Stokes equations with turbulence. The modeling approach is based on the model chosen by Wu and Chen (2008) making the following assumptions:

- 3-D and steady-state flow field

- incompressible and non-Newtonian fluid

- constant temperature $\left(43^{\circ} \mathrm{C}\right)$

- single-phase flow model

Rather than simulating the mixer blades, a simplified numerical model was developed calculating the tank flow field using volumetric flow rates. A system of differential equations is solved consisting of the continuity equation for the conservation of mass, the momentum equation for the momentum conservation and energy equations including a specific turbulence model.

The continuity equation that was solved looks like the following

$$
\frac{\partial u_{i}}{\partial x_{i}}=0
$$

where $u_{i}$ represents the fluid velocity in tensor form and $x_{i}$ are the components in the $i$ different directions.

The momentum equation is described by the following expression

$$
\frac{\partial}{\partial t}\left(\rho u_{i}\right)+\frac{\partial}{\partial x_{j}}\left(\rho u_{j} u_{i}\right)=-\frac{\partial p}{\partial x_{i}}+\frac{\partial \tau_{i j}}{\partial x_{j}}
$$

where $\rho$ is the fluid density and $p$ the static pressure. The shear stress $\tau_{i j}$ is dependent on the viscosity $\eta$ by

$$
\tau_{i j}=\eta\left(\frac{\partial u_{i}}{\partial x_{j}}+\frac{\partial u_{j}}{\partial x_{i}}\right)
$$

and the viscosity is dependent on the shear rate by the non-Newtonian Power Law model, i.e.

$$
\eta=K \dot{\gamma}^{n-1} \text { with } \eta_{\min } \leq \eta \leq \eta_{\max }
$$

The quantity $u_{j}$ represents the fluid velocity like $u_{i}$ above. Furthermore, $K$ represents the consistency coefficient, $\dot{\gamma}$ the shear rate and $n$ the Power Law index which expresses the fluid type, i.e. whether it is shear thinning $(n<1)$, Newtonian $(n=1)$ or shear thickening $(n>1)$.

The energy equations are derived by using the $k-\omega$ SST turbulence model. This model combines the benefits of 
the $k-\omega$ model and the $k-\epsilon$ model with a high Reynolds number. Thus, the turbulent kinetic energy $k$ and the dissipation rate $\omega$ can be modeled by differential equations.

The transport equation for the turbulent kinetic energy $(k)$ is represented by

$$
\frac{\partial}{\partial t}(\rho k)+\frac{\partial}{\partial x_{i}}\left(\rho u_{i} k\right)=\frac{\partial}{\partial x_{i}}\left[\left(\eta_{L}+\sigma_{k} \eta_{T}\right) \frac{\partial k}{\partial x_{i}}\right]+\tilde{P}_{k}-\beta^{\star} \rho \omega k
$$

and the transport equation for its dissipation rate $(\omega)$ is expressed by

$$
\frac{\partial}{\partial t}(\rho \omega)+\frac{\partial}{\partial x_{i}}\left(\rho u_{i} \omega\right)=\frac{\partial}{\partial x_{i}}\left[\left(\eta_{L}+\eta_{T} \sigma_{\omega}\right) \frac{\partial \omega}{\partial x_{i}}\right]+\alpha \rho S^{2}-\beta \rho \omega^{2}+2\left(1-f_{1}\right) \frac{\rho \sigma_{\omega_{2}}}{\omega} \frac{\partial k}{\partial x_{j}} \frac{\partial \omega}{\partial x_{j}},
$$

where $f_{1}$ is a function which combines the model coefficients of the $k-\omega$ model with the transformed $k-\epsilon$ model, i.e.

$$
f_{1}=\tanh \left(\left(\min \left(\max \left(\frac{\sqrt{k}}{\beta^{\star} \omega y}, \frac{500 \nu}{y^{2} \omega}\right), \frac{4 \rho \sigma_{\omega_{2}} k}{C D_{k \omega} y^{2}}\right)\right)^{4}\right)
$$

with

$$
C D_{k \omega}=\max \left(\frac{2 \rho \sigma_{\omega_{2}}}{\omega} \frac{\partial k}{\partial x_{j}} \frac{\partial \omega}{\partial x_{j}}, 10^{-10}\right)
$$

and $y$ describes the distance to the nearest wall. Moreover, the dynamic viscosity $\eta$ is given by the sum of the laminar viscosity $\eta_{L}$ and the turbulent viscosity $\eta_{T}$. (for details see Menter et al. (2003) or Blazek (2004, p. 61)). Furthermore, $\beta^{\star}$ represents a model constant. In order to prevent build up of turbulence in stagnation regions, a production limiter is used which is described by $\tilde{P}_{k}$ with

$$
P_{k}=\eta_{T} \frac{\partial u_{i}}{\partial x_{j}}\left(\frac{\partial u_{i}}{\partial x_{j}}+\frac{\partial u_{j}}{\partial x_{i}}\right) \rightarrow \tilde{P}_{k}=\min \left(P_{k}, 10 \beta^{\star} \rho k \omega\right)
$$

The coefficients of the SST turbulence model $\beta, C_{\omega}, \sigma_{k}$ and $\sigma_{\omega}$ result from a combination of the coefficients of the $k-\omega$ model with the coefficients of the transformed $k-\epsilon$ model. The parameter $\alpha$ is calculated by

$$
\alpha=\alpha_{1} f+\alpha_{2}(1-f)
$$

The other constants are $\beta^{\star}=0.09, \alpha_{1}=5 / 9, \beta_{1}=3 / 40, \sigma_{k_{1}}=0.85, \sigma_{\omega_{1}}=0.5, \alpha_{2}=0.44, \beta_{2}=0.0828, \sigma_{k_{2}}=1$, $\sigma_{\omega_{2}}=0.856$. The turbulence viscosity is obtained using

$$
\eta_{T}=a_{1} \frac{k}{\max \left(a_{1} \omega, b_{1} f_{2} S\right)}
$$

\subsection{CFD Simulation of the Biogas Plant}

The structure of the simulation using the different software can be found in Figure 3. 


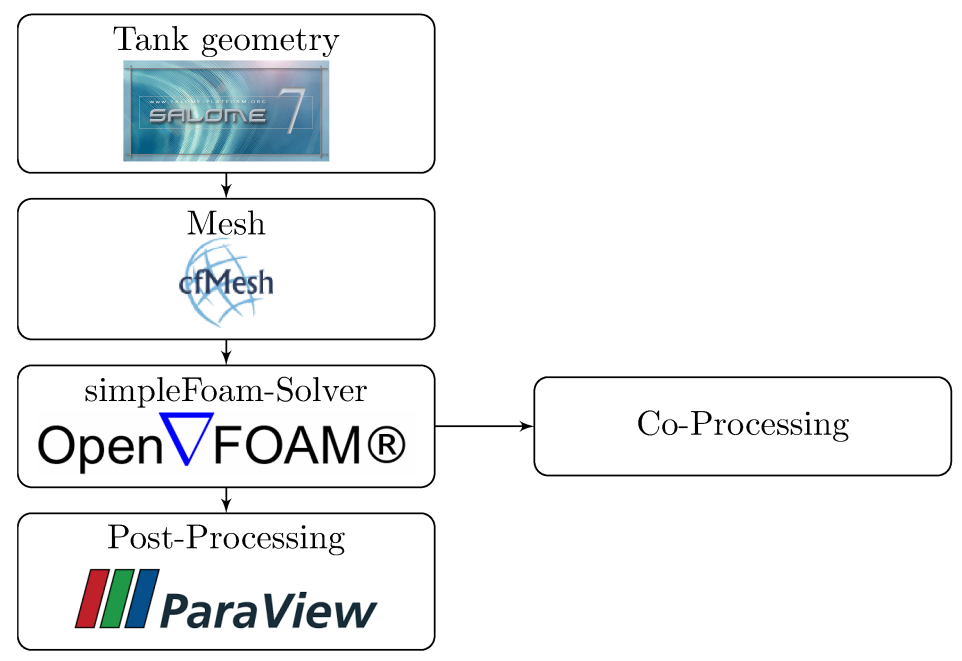

Figure 3: Simulation setup

The geometry is generated with Salome and then exported to a python script. The model is kept as simple as possible due to the computational expenses that can be expected when also putting an optimization framework around it. The mesh is generated using cfMesh (version 1.1.1). We define the maximum length of a cell in the calculation area as $0.2 \mathrm{~m}$ and as $0.05 \mathrm{~m}$ for the surface cells. The resulting mesh consists of 132000 mostly hexaedric cells with a maximum cell volume of $0.008 \mathrm{~m}^{3}$. The total volume of the whole tank geometry corresponds to $949.83 \mathrm{~m}^{3}$ and is illustrated in Figure 2.

\begin{tabular}{lll}
\hline Term & Method & OpenFOAM $^{7}$ \\
\hline Time & - & steadyState \\
Gradient & Gauss & cellLimited Gauss linear 1 \\
Divergence & Gauss & bounded Gauss linearUpwind grad \\
Laplace & Gauss & Gauss linear limited 0.333 \\
Interpolation & - & linear \\
\hline
\end{tabular}

Table 1: Overview of the used numerical schemes for the CFD simulations oft the biogas plant

We compute the stationary solution of the $\mathrm{CFD}^{1}$ simulation with OpenFOAM ${ }^{7}$ (version 2.4.0). Thereby we use the solver simpleFOAM ${ }^{7}$ in combination with the $k-\omega$ SST model for the solution of the coupled system of differential equations. In detail the numerical schemes displayed in Table 1 are used. The initial and boundary conditions are chosen according to Table 2 . The volumetric flow rate is set to $1.75 \mathrm{~m}^{3} \mathrm{~s}^{-1}$ according to the specification of the manufacturer of the mixer. This is included in a R-script which is used to compute the velocity and direction of the inflowing substrate at the inlet. In detail the velocity at the inlet $\left(U_{i n}\right)$ is calculated by

$$
U_{i n}=\frac{\dot{V}}{\pi r_{i n}^{2}}
$$




\begin{tabular}{|c|c|c|c|}
\hline Boundary & Field & OpenFOAM ${ }^{7} \mathbb{R}$ Condition & Value \\
\hline Tank & $U$ & fixedValue & $\left(\begin{array}{lll}0 & 0 & 0\end{array}\right)$ \\
\hline Tank & $p$ & zeroGradient & - \\
\hline Tank & $k$ & kqrWallFunction & $1 \times 10^{-20}$ \\
\hline Tank & $\omega$ & omegaWallFunction & $1 \times 10^{-2}$ \\
\hline Inlet & $U$ & fixedValue & $\left(\begin{array}{lll}-3.095 & 5.360 & 0\end{array}\right)^{1}$ \\
\hline Inlet & $k$ & fixedValue & $1 \times 10^{-1}$ \\
\hline Inlet & $\omega$ & fixedValue & $1 \times 10^{-2}$ \\
\hline Inlet & $p$ & zeroGradient & - \\
\hline Outlet & $U, k, \omega$ & zeroGradient & - \\
\hline Outlet & $p$ & totalPressure & 0 \\
\hline
\end{tabular}

${ }^{1}$ according to the volumetric flow rate of $1.75 \mathrm{~m}^{3} \mathrm{~s}^{-1}$ in the standard case (tangential inlet in an angle of $60^{\circ}$ )

Table 2: Overview of the used boundary and initial conditions for the CFD simulations of the biogas plant

where $\dot{V}$ denotes the volumetric flow rate and $r_{i n}$ stands for the inlet radius which is considered to be $0.3 \mathrm{~m}$ in our case. This results in an inlet velocity $U_{\text {in }}$ of $6.19 \mathrm{~ms}^{-1}$. The velocity is expressed as a vector along the $\mathrm{x}$-axis which can then be transformed by vector transformation. This is realized using the R-function rotate3D with the horizontal and vertical influx angle. For the latter computation we perform vector rotations with the angle $\alpha$ around the y-axis (as in Eq. (9)) and with the angle $\beta$ around the z-axis (as in Eq. (10)).

$$
\begin{aligned}
& R_{y}(\alpha)=\left(\begin{array}{ccc}
\cos (\alpha) & 0 & \sin (\alpha) \\
0 & 1 & 0 \\
-\sin (\alpha) & 0 & \cos (\alpha))
\end{array}\right) \\
& R_{z}(\beta)=\left(\begin{array}{ccc}
\cos (\beta) & -\sin (\beta) & 0 \\
\sin (\beta) & \cos (\beta) & 0 \\
0 & 0 & 1
\end{array}\right)
\end{aligned}
$$

For the OpenFOAM ${ }^{7}$ rheology model powerLaw, we use the values from Table 4 as explained in detail later in Section 2.5.2.

\subsection{Optimization}

The coupling of the $\mathrm{CFD}^{1}$ simulation with the optimization can be found in Fig. 4. For this coupling procedure, the response metrics (design function) of the $\mathrm{CFD}^{1}$ simulation $\left(\mathrm{OpenFOAM}^{7}\right.$ ) are handed as an output file to the optimization level (DAKOTA $\left.{ }^{4}\right)$. The optimization integrates this output into the algorithm and an optimization problem is solved for the design parameters. These design parameters are then handed to the computational model in form of an input file again. This methodology is also called black box approach because DAKOTA ${ }^{4}$ does not interact with the simulation code itself and just processes the input parameters in a given format. 


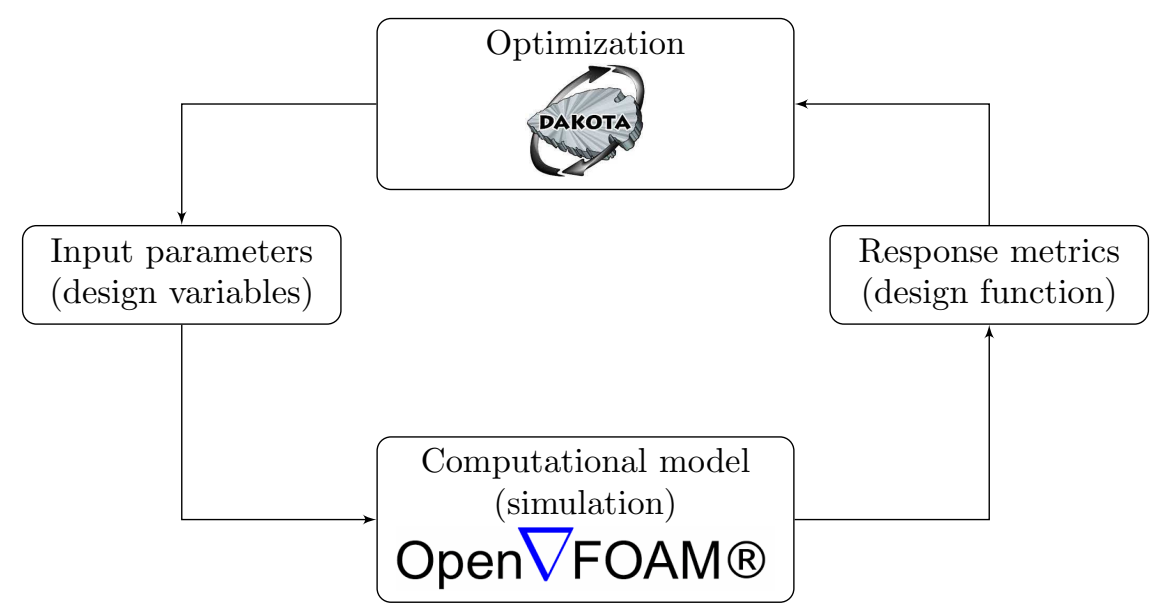

Figure 4: Optimization setup

\subsubsection{Geometry and Optimization Parameters}

The height of the modeled fermenter is $10 \mathrm{~m}$ and it has a radius of $5.5 \mathrm{~m}$. The external mixer is fed through a pipe with a radius of $0.6 \mathrm{~m}$ that exits the tank at $9 \mathrm{~m}$ height and pumps the substrate back at $0.5 \mathrm{~m}$ above the tank bottom. The optimization software requires the input parameters to be varied as well as the objective parameter to be optimized. Input parameters are the rotation angle of the outlet with respect to the inlet on the tank wall $\left(0^{\circ}\right.$ to $\left.360^{\circ}\right)$ and the influx vectors in the vertical $\left(-45^{\circ}\right.$ to $\left.45^{\circ}\right)$ and horizontal $\left(0^{\circ}\right.$ to $\left.70^{\circ}\right)$ plane at the inlet. These will be denoted $\theta$ or $\theta_{1}, \theta_{2}, \theta_{3}$ in the following. The objective variable is based on the volume in the tank in which the substrate is moving with a velocity less than $\varepsilon$, where $\varepsilon\left[\mathrm{ms}^{-1}\right]$ is chosen, such that

$$
\int_{V} \chi_{[0, \varepsilon]}\left(U_{m a g}(\theta)\right) d c=475 \mathrm{~m}^{3} .
$$

The threshold $\varepsilon$ is chosen based on where the volume integral of a dirac delta function $\chi_{[0, \varepsilon]}$ dependent on the magnitude velocity of cell $\theta$ is equal to half of the total tank volume of approximately $950 \mathrm{~m}^{3}$ for the standard geometry with the coordinates $(0,0,60)$. The standard geometry is the geometry used by our industry partner with the rotation angle of the outlet with respect to the inlet of $0^{\circ}$, with a vertical inflow angle of $0^{\circ}$ and with a horizontal inflow angle of $60^{\circ}$. Thereby $\chi_{[0, \varepsilon]}\left(U_{\text {mag }}(\theta)\right)$ with $\chi_{[0, \varepsilon]}: \Theta \rightarrow\{0,1\}$ is defined by

$$
\chi_{[0, \varepsilon]}\left(U_{m a g}(\theta)\right):= \begin{cases}1, & \text { if } U_{m a g}(\theta) \in[0, \varepsilon] \\ 0, & \text { else } .\end{cases}
$$

where $\Theta$ is the space of cells. The calculated values for $\varepsilon$ are shown in Table 3 . They divide the tank volume into a slow and fast moving zone for the different dry substance contents. The slow moving zone is called dead volume zone throughout this work. 


\begin{tabular}{rc}
\hline $\begin{array}{c}\mathrm{DSC}^{6} \\
\text { (in \%) }\end{array}$ & $\begin{array}{c}\text { Velocity Threshold } \varepsilon \\
\text { (in } \mathrm{m} \mathrm{s}^{-1} \text { ) }\end{array}$ \\
\hline 2.5 & 1.25 \\
3.95 & 1.17 \\
5.4 & 1.13 \\
6.45 & 1.00 \\
7.5 & $9.49 \times 10^{-1}$ \\
8.3 & $9.14 \times 10^{-1}$ \\
9.1 & $8.92 \times 10^{-1}$ \\
10.6 & $4.39 \times 10^{-1}$ \\
12.1 & $3.27 \times 10^{-1}$ \\
\hline
\end{tabular}

Table 3: Overview of the calculated thresholds for the maximum velocity in the slow-moving zone for the different dry substance contents

\subsubsection{Substrate Characteristics}

The biogas substrate is modeled as an incompressible and non-Newtonian fluid. It was not possible within the scope of this study to determine the rheological properties in the biogas plant and according to the plant operator measured rheological values would have only been useful to limited extend as the composition changes significantly over time. That is why we use multiple sets of experimental data for each simulation iteration as already used in the study of Wu and Chen (2008) from (Achkari-Begdouri and Goodrich, 1992) and (Landry et al., 2004) (see Table 4). In addition to these literature values, interpolated quantities are used in this study which are highlighted in gray in Table 4. In other words, the values for $\operatorname{DSC}^{6} 3.95,6.45,8.3$ and $10.6 \%$ are interpolated values and the other ones are literature values. The arithmetic or weighted arithmetic mean of the resulting dead volumes for each substrate is therefore the actual objective parameter. The consideration of different substrate characteristics ensures a robust model to optimize the input parameters across a wide spectrum of biogas substrates. From the data provided by BGA Warsow GmbH \& Co.KG the most likely occuring dry substance content (DSC ${ }^{6}$ ) lies between 9 and $10 \%$ and a dry substance content above $10.5 \%$ yields stress. $\mathrm{A} \mathrm{DSC}^{6}$ below $3.8 \%$ is improbable.

\begin{tabular}{lllllll}
$\mathrm{DSC}^{6}(\%)$ & $\mathrm{K}\left(\mathrm{Pa} s^{n}\right)$ & $\mathrm{n}$ & $\dot{\gamma}\left(\mathrm{s}^{-1}\right)$ & $\min (\mathrm{Pa} \cdot \mathrm{s})$ & $\eta_{\max }(\mathrm{Pa} \cdot \mathrm{s})$ & $\rho\left(\mathrm{kg} / \mathrm{m}^{3}\right)$ \\
\hline 2.5 & 0.042 & 0.71 & $226-702$ & 0.006 & 0.008 & 1000.36 \\
3.95 & 0.117 & 0.636 & $138-702$ & 0.008 & 0.019 & 1000.57 \\
5.4 & 0.192 & 0.562 & $50-702$ & 0.01 & 0.03 & 1000.78 \\
6.45 & 0.333 & 0.5475 & $36-550.5$ & 0.02 & 0.1 & 1000.89 \\
7.5 & 0.525 & 0.533 & $11-399$ & 0.03 & 0.17 & 1001 \\
8.3 & 0.7885 & 0.5 & $11-277.5$ & 0.05 & 0.23 & 1001.155 \\
9.1 & 1.052 & 0.467 & $11-156$ & 0.07 & 0.29 & 1001.31 \\
10.6 & 3.4685 & 0.417 & $7-152.5$ & 0.16 & 1.61 & 1001.52 \\
12.1 & 5.885 & 0.367 & $3-149$ & 0.25 & 2.93 & 1001.73 \\
\hline
\end{tabular}

Table 4: Rheological properties from (Wu and Chen, 2008) and interpolated values highlighted in gray

\subsubsection{Optimization under Uncertainties}

As the consistence of the biogas substrate is very uncertain and has a remarkable impact on the rheological properties, the $\mathrm{DSC}^{6}$ is included in the model as an uncertainty. One could also look for the optimal geometry 


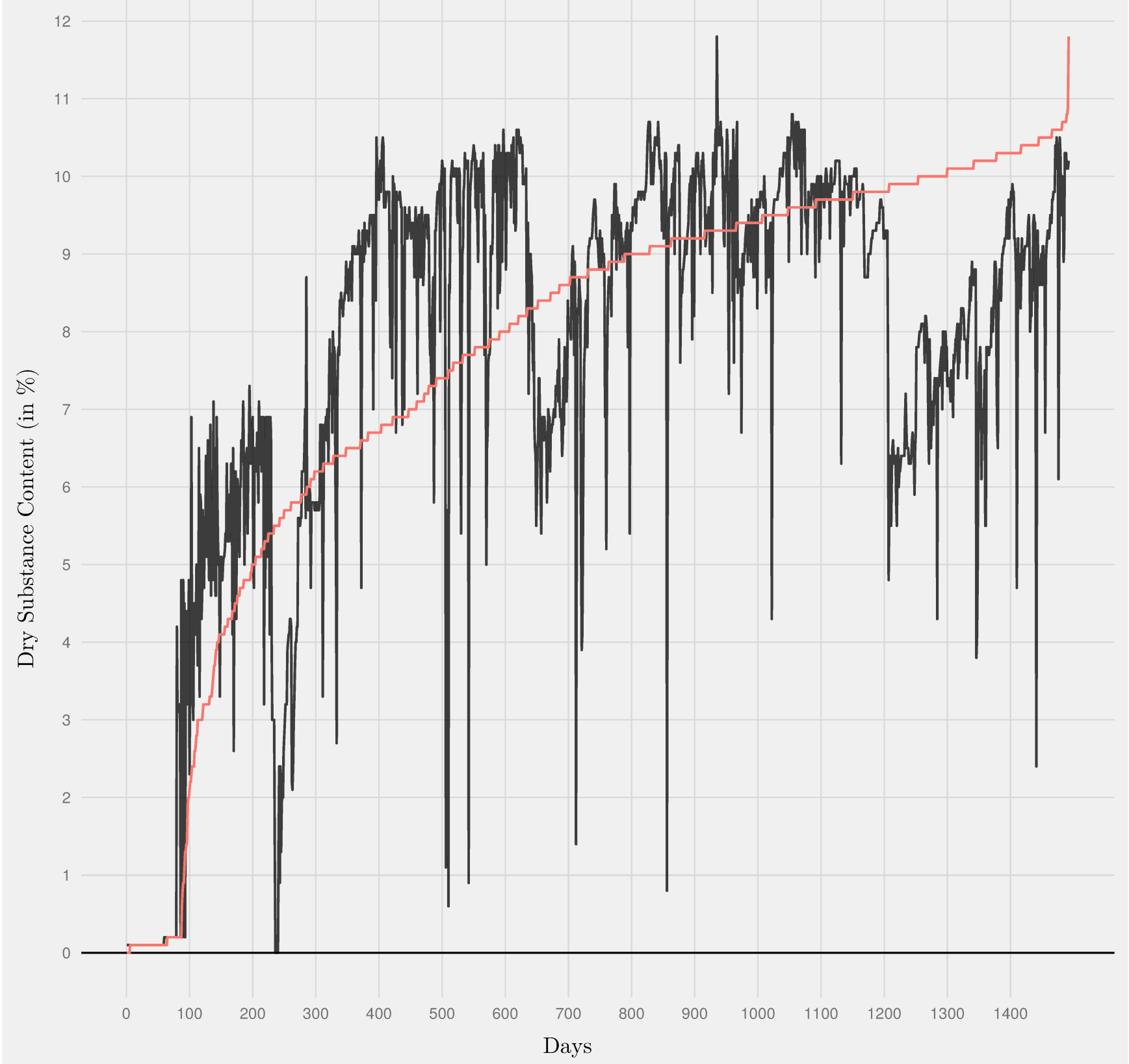

Figure 5: Daily measured dry substance content in the biogas plant in Warsow over 1492 days (Dec 1, 2012-Jan 1, 2017). In black the measurements in chronological order and in red the distribution in increasing order (Generated with data provided by BGA Warsow $\mathrm{GmbH} \& \mathrm{Co.KG})$

for each single $\mathrm{DSC}^{6}$ but this would yield different optimal solutions. In this scenario the tank geometry would need to be modified depending on the actual $\mathrm{DSC}^{6}$ considered. This approach is not practical and too costly, which is why it is preferable to find an optimal solution in a weighted sense for all different DSCs ${ }^{6}$. In this context nine different $\operatorname{DSCs}^{6}$ (see Table 4) are considered. The weighted arithmetic mean or arithmetic mean of the dead volumes resulting from the different $\mathrm{DSCs}^{6}$ is minimized. For the weighted arithmetic mean the weights are chosen 
based on the data provided by BGA Warsow GmbH \& Co.KG, illustrated in Fig. 5, i.e.

$$
\begin{gathered}
\zeta=(0,0.0120,0.0528,0.0945,0.1353,0.1761,0.2179,0.1761,0.1353)^{T} \quad \text { with } \\
\sum_{i=1}^{9} \zeta_{i}=1 .
\end{gathered}
$$

The objective function is formulated as

$$
\Phi(d)=\zeta^{T} d
$$

with $d=\left(d_{1}, \ldots, d_{9}\right)^{T}$ where $d$ is the dead volume vector with the dead volumes resulting from the 9 different dry substance contents. This means that in terms of terminology we assume two different weight distributions and then the objective is represented by the expected mean value of the events and weights representing their occurrence. Thus our objective represents the expected costs assuming two different weight distributions. In terms of optimization under uncertainties one usually distinguishes between robust optimization and stochastic programming. The main difference is that for stochastic programming one assumes the probability distribution of the uncertain data to be known. In contrast to this, for robust optimization one does not make this assumption but assumes that the uncertain data set can be represented by an uncertainty set. With this approach one generates a solution that is optimal in some sense for all uncertainties chosen from the uncertainty set. More information on the differences in between these two approaches can be found e.g. in (Gorissen et al., 2015, Bertsimas et al., 2011). Here, the considered robust optimization problem is described by

$$
(P)\left\{\begin{array}{c}
\min _{\theta_{1}, \theta_{2}, \theta_{3}} \Phi(d) \\
\text { s.t. Black Box Model } \\
0 \leq \theta_{1} \leq 360 \\
-45 \leq \theta_{2} \leq 45 \\
0 \leq \theta_{3} \leq 70
\end{array}\right.
$$

where the black box model corresponds to the OpenFOAM ${ }^{7}$ model. As the optimization method of choice, the DIRECT $^{5}$ (DIviding RECTangles) method (Jones et al., 1993) is used. This is a deterministic direct search sampling method where, starting with a hyperrectangle, the space is divided along the set of longest sides. Convergence results can be found in Finkel and Kelley (2004).

\section{Results and Discussion}

As explained in Section 2.5.1, the velocity thresholds for the definition of the dead volume zone are calculated first based on the original configuration (see Table 3). Most of the following results were computed on a cluster 
at Trier University with four AMD Opteron ${ }^{\text {TM }} 6176$ SE Multi-Core-Processors (12 cores each) and 264 GB RAM. The calculations for the weighted robust mean optimization were run on a DellPrecision Tower 7810 Workstation with two Intel Xeon E5-2660 v3 Multi-Core-Processors (10 cores each) and 64 GB RAM (8x8 GB@2133 MHz) at Hochschule Geisenheim University.

The original configuration of the biogas plant in Warsow (Original Configuration) is compared to the single-set optimization approach (Single Opt.) for individual $\mathrm{DSCs}^{6}$, the robust optimization approach using the arithmetic mean of the individual volumes for the objective function (Mean Opt.) and the robust optimization approach using the weighted arithmetic mean of the individual volumes as the objective function with the weights chosen as explained in Section 2.5.3 (Weighted Mean Opt.). The results for the $\mathrm{DSC}^{6}$, the design parameters, i.e. variables $x_{1}, x_{2}$ and $x_{3}$ and the objective value are highlighted in Table 5 . In the single-set optimizations the dead volume zone was reduced on average by $27.9 \%$ or $132.4 \mathrm{~m}^{3}$, respectively. In the robust optimization approaches, the total dead volumes were also reduced compared to the original cases. For the lower $\operatorname{DSCs}^{6}(3.95 \%-6.45 \%)$ the resulting slow moving volume is much smaller than for the higher $\operatorname{DSCs}^{6}(7.5-12.1 \%)$. For the arithmetic mean case the total dead volume zone was reduced by $21.68 \%$ or $102.9 \mathrm{~m}^{3}$ and for the weighted arithmetic mean case even by $23.21 \%$ or $110.2 \mathrm{~m}^{3}$.

As the dead volume zone is defined by the tank volume and not by an empirical value, the development of the velocities below the threshold is investigated as well. For this purpose we divide the cells of the dead volume zone into 5 areas, which are defined by their percental dependence on the individual velocity threshold. For example the velocity threshold for $6.45 \% \mathrm{DSC}^{6}$ corresponds to exactly $1.00 \mathrm{~ms}^{-1}$ (see Table 3 ). Thus the volume of the area with the lowest velocity in Fig. 7 corresponds to the summed up volume of all cells with a velocity of less than $0 \mathrm{~ms}^{-1}$ to $0.2 \mathrm{~ms}^{-1}$. The sum of all the five areas is equal to half the tank volume, i.e. $475 \mathrm{~m}^{3}$ or the total dead volumes resulting from the optimization approaches illustrated in Fig. 6. Figure 7 shows the deviating behavior of the two highest $\operatorname{DSCs}^{6}$ (10.6\% and 12.1\%) from the other ones. For the lower DSCs ${ }^{6}$ the volumes decrease almost linearly for the five velocity areas but for the two highest $\mathrm{DSCs}^{6}$ the velocity areas from $20 \%$ to $80 \%$ contribute much more to the total dead volume zone. Figure 6 indicates that the single optimization approach results in the smallest dead volume zone for all DSCs ${ }^{6}$. However, Fig. 7 shows that this is only the case for almost all areas. The weighted arithmetic mean robust optimization results in a smaller total dead volume zone than the arithmetic mean robust optimization but in Fig. 6 it becomes evident that the arithmetic mean outperforms the weighted one for all $\mathrm{DSCs}^{6}$ which were given a low weight (e.g. the lowest and the highest ones).

The resulting dead volume zones for the different $\mathrm{DSCs}^{6}$ are illustrated in Fig. 8. For all cases a column of slow velocity forms in the middle of the tank but with the different optimization approaches its volume can be reduced by a significant amount. The single optimization outperforms the other optimization approaches with respect to the resulting objective value. However, as already mentioned above, we can not adjust the design parameters of the plant during the fermentation, such that the robust optimization approaches result in the most useful results in 


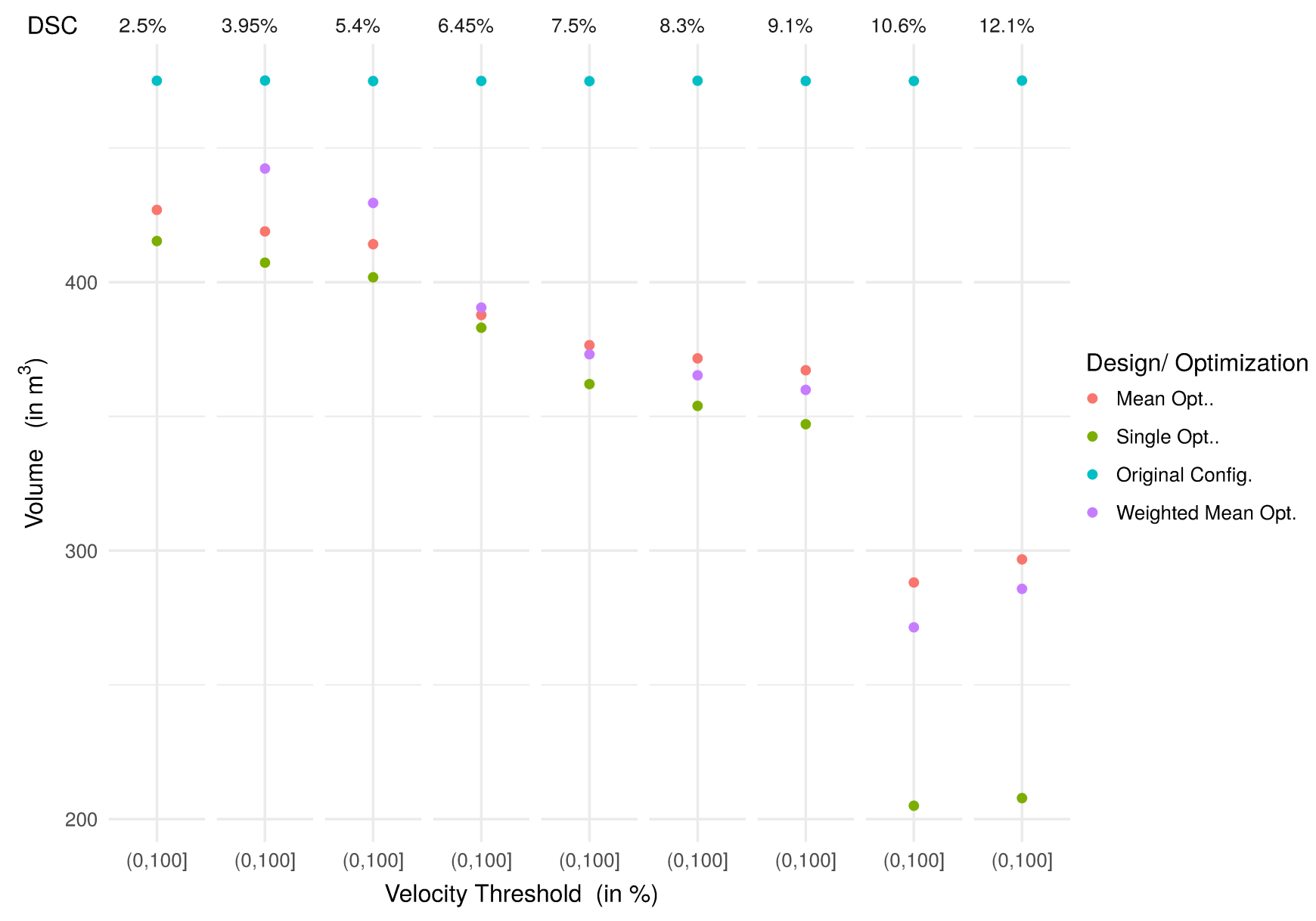

Figure 6: Calculated volume of the dead volume zone for the original configuration (0-0-60) and after three optimization approaches (Single Optimization for the individual DSCs and robust optimization with arithmetic and weighted arithmetic mean as objective) 


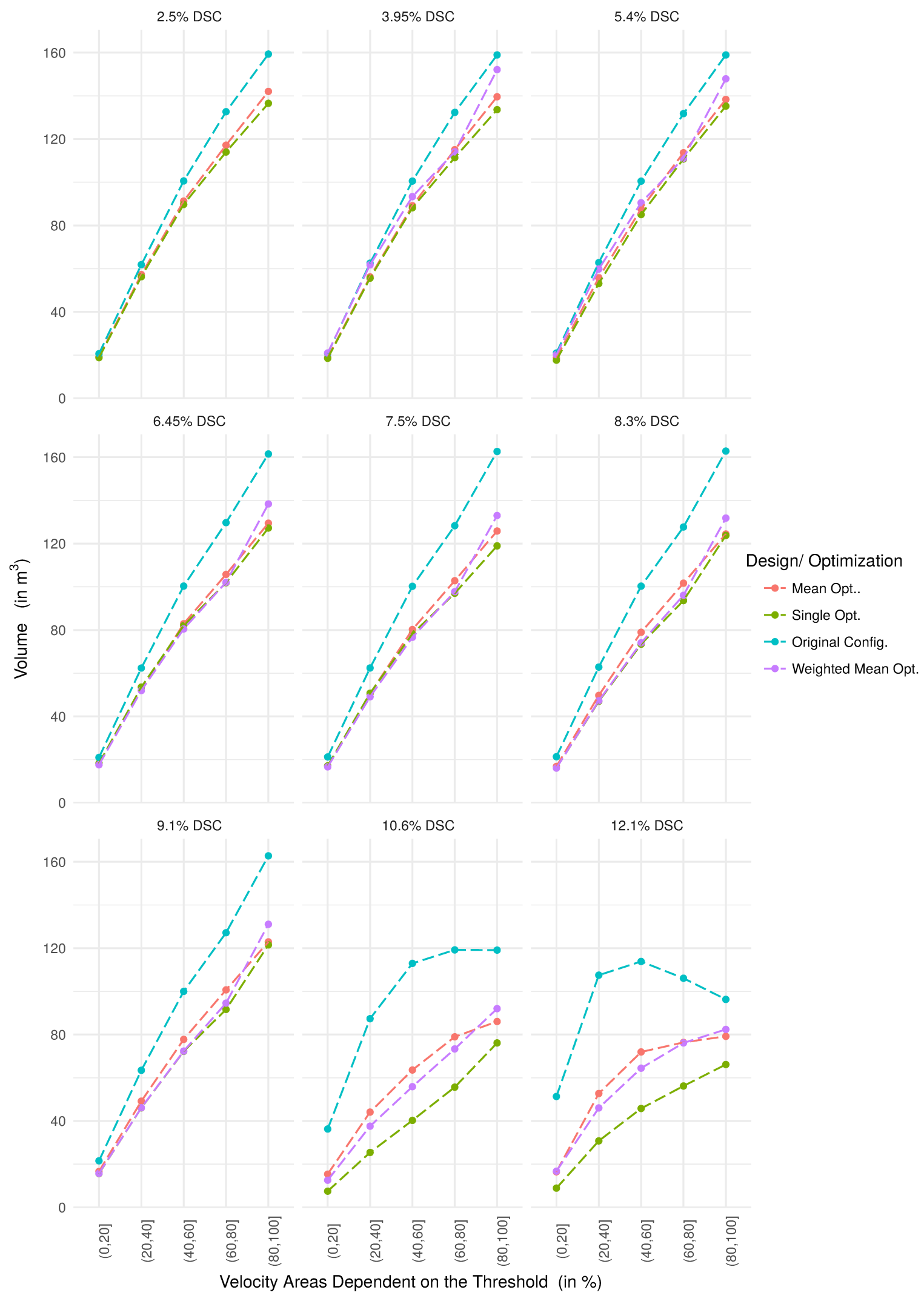

Figure 7: Volumes of five velocity areas inside the dead volume zone for the original configuration (0-0-60) and after three optimization approaches (Single Optimization for the individual DSCs and robust optimization with arithmetic and weighted arithmetic mean as objective) 
practice. Fig. 8 shows that with increasing DSC $^{6}$ slow moving areas also form close to the tank wall for the original configuration and for the two highest $\mathrm{DSCs}^{6}$ slow moving areas also form close to the surface. Those areas are the ones that can be eliminated with all three optimization approaches by optimizing the design variables.

The original and optimal parameter configurations are described in Table 5. The outlet position varies a lot $\left(\theta_{1}\right.$, $\left(0^{\circ}\right.$ to $\left.360^{\circ}\right)$ ) and results in differences of up to $174^{\circ}$ from the inlet for the single optimizations (for $\operatorname{DSC}^{6}$ of $3.95 \%$ ). The solution for $\theta_{1}$ for the single optimizations from 6.45 to $9.1 \% \mathrm{DSC}^{6}$ and for the weighted arithmetic mean optimization is located more than $180^{\circ}$ away from the inlet (in tangential flow direction). For all $\mathrm{DSC}^{6}$ apart from the two lowest ones, the optimal outlet position is located between 80 and $120 \%$ away from the inlet (in and against flow direction). The vertical angle of the inflow $\left(\theta_{2},\left(-45^{\circ}\right.\right.$ to $\left.45^{\circ}\right)$ does not show a trend with respect to variance of the $\mathrm{DSC}^{6}$. For the lower $\mathrm{DSC}^{6}$ (up to 9.1\%) pumping it in downwards up in an angle up to $15^{\circ}$ is optimal. For the higher $\operatorname{DSC}^{6}(10.6 \%$ and $12.1 \%)$ and the robust optimization approaches the result for $\theta_{2}$ is located around $0^{\circ}$ (for $10.6 \%$ and $12.1 \%$ even slightly upwards). The result of the single optimization for the horizontal angle of the inflow $\left(\theta_{3},\left(0^{\circ}\right.\right.$ to $\left.\left.70^{\circ}\right)\right)$ decreases continuously with increasing $\mathrm{DSC}^{6}$. The optimal value for lower $\operatorname{DSCs}^{6}$ is located around $45^{\circ}$ and for higher $\operatorname{DSCs}^{6}$ it is located around $25^{\circ}$. For the robust optimization approaches, the optimal value is located around $43^{\circ}$ for the arithmetic mean case and around $35^{\circ}$ for the weighted arithmetic mean case.

\begin{tabular}{crrrrr}
\hline Design / Optimization & $\begin{array}{r}\mathrm{DSC}^{6} \\
\text { (in \%) }\end{array}$ & $\begin{array}{r}\text { Variable } \theta_{1} \\
\left(0^{\circ} \text { to } 360^{\circ}\right)\end{array}$ & $\begin{array}{r}\text { Variable } \theta_{2} \\
\left(-45^{\circ} \text { to } 45^{\circ}\right)\end{array}$ & $\begin{array}{r}\text { Variable } \theta_{3} \\
\left(0^{\circ} \text { to } 70^{\circ}\right)\end{array}$ & $\begin{array}{r}\text { Objective Value } \\
\left(\text { in } \mathrm{m}^{3}\right)\end{array}$ \\
\hline Original Configuration & 2.5 to 12.1 & 0.00 & 0.00 & 60.00 & 475.00 \\
Single Opt. & 2.5 & 158.56 & -3.33 & 45.75 & 415.32 \\
Single Opt. & 3.95 & 173.58 & -4.49 & 45.37 & 408.60 \\
Single Opt. & 5.4 & 85.74 & -12.78 & 41.29 & 401.82 \\
Single Opt. & 6.45 & 263.85 & -1.65 & 37.29 & 383.04 \\
Single Opt. & 7.5 & 265.00 & -14.77 & 39.03 & 362.04 \\
Single Opt. & 8.3 & 253.26 & -13.31 & 35.00 & 353.92 \\
Single Opt. & 9.1 & 245.07 & -11.56 & 34.90 & 347.10 \\
Single Opt. & 10.6 & 119.72 & 4.07 & 26.65 & 205.01 \\
Single Opt. & 12.1 & 112.29 & 0.69 & 24.36 & 207.85 \\
Mean Opt. & 2.5 to 12.1 & 116.29 & -2.22 & 42.99 & 372.00 \\
Weighted Mean Opt. & 3.95 to 12.1 & 273.28 & -1.66 & 34.57 & 344.60 \\
\hline
\end{tabular}

Table 5: Optimized designs for minimization of the slow-moving zone in the biogas plant

The computation times are presented in Table 6 where the mean optimization was the most computationally expensive. As mentioned above, the weighted mean optimization was run on a cluster at Hochschule Geisenheim University. All other computations were performed on a cluster at Trier University. The weighted mean case converged to a solution after 9.7 days where the mean case only converged to a solution after 26.5 days. The last column in Table 6 illustrated the number of evaluations which represent the number of different parameter configurations that were evaluated by the DIRECT ${ }^{5}$ method before the optimal configuration was determined. Apart from the simulation for $10.6 \% \mathrm{DSC}^{6}$, which took 461 evaluations, an average of 250.9 evaluations were made. The simulation for $5.4 \% \mathrm{DSC}^{6}$ took way longer (8.8 days) than the other ones with an average of 2.94 days. 
Original Configuration Single Opt.

DSC $2.5 \%$

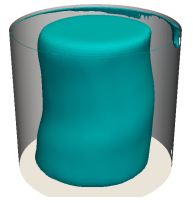

DSC $3.95 \%$

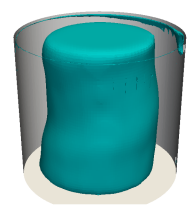

DSC 5.4\%

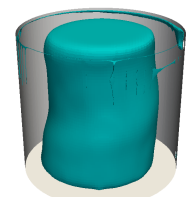

DSC $6.45 \%$

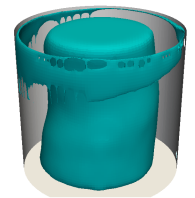

DSC $7.5 \%$

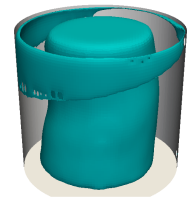

DSC $8.3 \%$

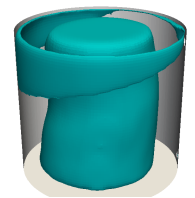

DSC $9.1 \%$
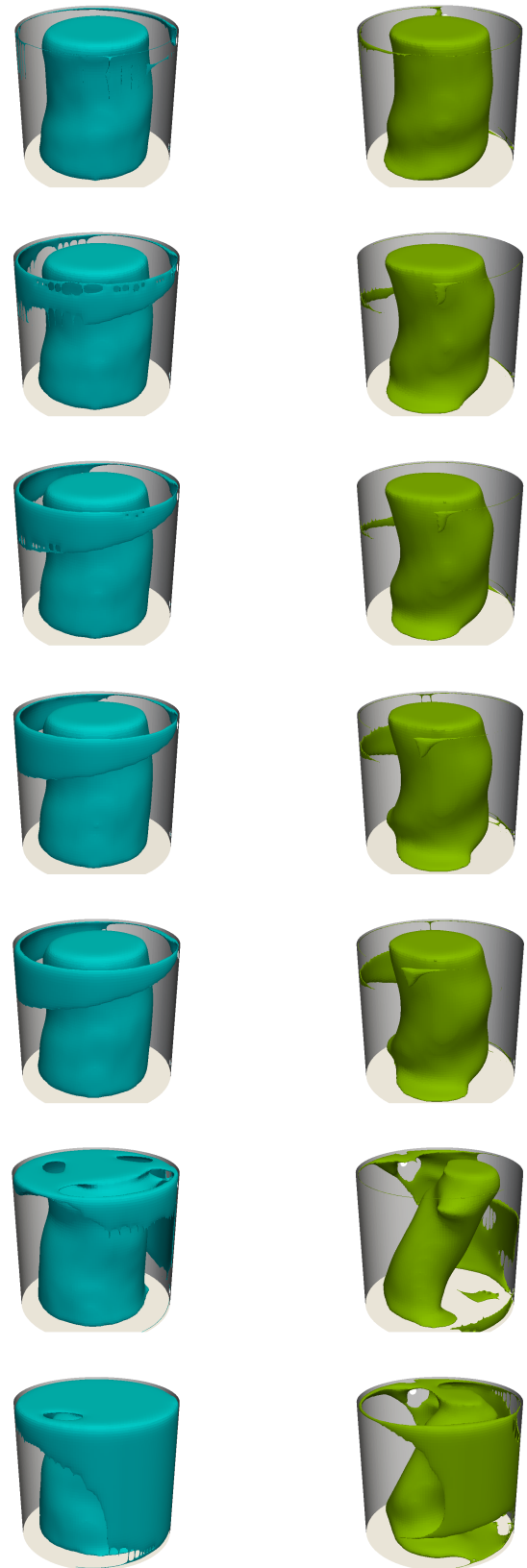

Mean Opt. Weighted Mean Opt.
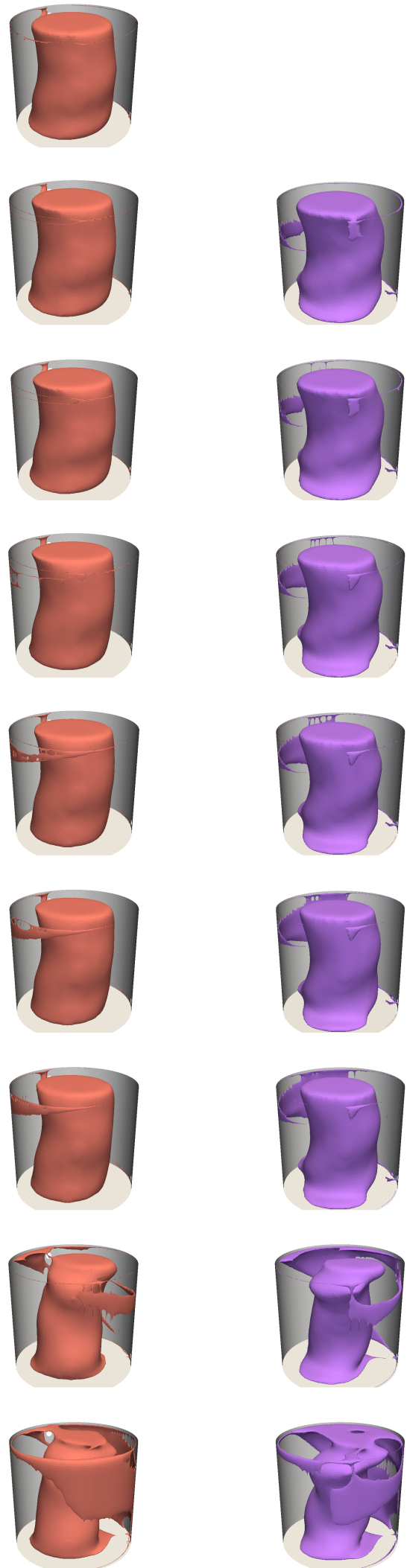

Figure 8: 3D-Illustration of the slow-moving zone for the standard configuration (blue) and the different optimizations $($ single $=$ green, mean $=$ red, weighted mean $=$ purple) 


\begin{tabular}{llrrr}
\hline & & \multicolumn{2}{c}{ Computation Time } & \\
\cline { 3 - 4 } Optimization & DSC $^{6}$ & in s & in days & Evaluations \\
\hline Single & $2.5 \%$ & 303228 & 3.5 & 271 \\
Single & $3.95 \%$ & 140064 & 1.6 & 237 \\
Single & $5.4 \%$ & 757291 & 8.8 & 313 \\
Single & $6.45 \%$ & 212714 & 2.5 & 211 \\
Single & $7.5 \%$ & 202758 & 2.3 & 234 \\
Single & $8.3 \%$ & 190107 & 2.2 & 209 \\
Single & $9.1 \%$ & 220509 & 2.5 & 289 \\
Single & $10.6 \%$ & 484580 & 5.6 & 461 \\
Single & $12.1 \%$ & 275053 & 3.2 & 225 \\
Mean & $2.5 \%$ to $12.1 \%$ & 2293030 & 26.5 & 299 \\
Weighted Mean & $3.95 \%$ to $12.1 \%$ & 840743 & 9.7 & 221 \\
\hline
\end{tabular}

Table 6: Computation times of the CFD-based optimization for minimization of the slow-moving zone in the biogas plant (all except the weighted mean optimization computed in parallel on 18 cores)

\section{Conclusions}

To determine the optimal configuration of an external mixer in an industrial biogas fermenter, a $\mathrm{CFD}^{1}$ simulation $\left(\right.$ OpenFOAM $\left.^{7}\right)$ was coupled with an optimization procedure $\left(\mathrm{DAKOTA}^{4}\right)$. To determine the optimal external mixer installation parameters the $\mathrm{CFD}^{1}$ model was derived and the optimization problem was formulated. It was applied to an actual biogas fermenter comprising $950 \mathrm{~m}^{3}$. As the viscosity properties of the non-Newtonian substrate change continuously inside the fermenter, a problem formulation that has the capability of finding the optimal configuration with respect to these changing viscosity properties was required. The problem was formulated using a robust optimization approach taking the dry substance content as uncertainty into account. Two objectives were investigated, the arithmetic mean and the weighted arithmetic mean of the volume of the corresponding dead volume zones. The weights for the weighted objective were determined by a calculation from a measured distribution. The underlying simulations were solved in parallel. The implemented solution strategy resulted in a configuration that is optimal on average throughout the production process. For comparison purposes, the single-set problems for each individual $\mathrm{DSC}^{6}$ were also optimized. The results from the three optimization approaches were compared to the original configuration. The results approved the hypothesis of a forming zone in the middle of the tank in the shape of a column. The $\mathrm{CFD}^{1}$ optimization showed that the dead volume zone, defined by a relative velocity threshold, can be reduced by more than $20 \%$ with respect to the different $\mathrm{DSCs}^{6}$. In the original configuration the outlet was directly located above the inlet. However, the optimal configuration parameters show that this is not the best location where the optimal values range from $85.75^{\circ}$ to $273.28^{\circ}$ compared to $0^{\circ}$ in the original configuration. Moreover, the substrate should be pumped in less tangentially than in the original configuration. More precisely the values for the horizontal inflow angle range from $24.36^{\circ}$ to $45.75^{\circ}$. Furthermore, the value of the vertical angle of the inflow of the original configuration lies in the resulting optimal range. Thus, the original setup for that parameter was already fairly good. All of the software used for the scope of this study is open-source. The outcomes of this work can be very useful in particular for mixer placements in large tanks or for installations of industrial fermenters. 
Thus, plant manufacturers and operators can benefit from these results.

\section{Acknowledgements}

This research work was funded by the German Federal Ministry of Education and Research (BMBF, Bundesministerium für Bildung und Forschung) within the collaborative project R(ENOBIO ${ }^{8}$ with contract number 05M2013UTA. Moreover, it has been partly supported by the German Research Foundation (DFG) within the research training group 2126 Algorithmic Optimization. Furthermore, many thanks goes to our joint and associated partners within the project R(ENOBIO ${ }^{8}$.

\section{References}

A. Achkari-Begdouri and P. R. Goodrich. Rheological Properties of Moroccan Dairy Cattle Manure. Bioresource Technology, 40(2):149 - 156, 1992. ISSN 0960-8524. doi: https://doi.org/10.1016/0960-8524(92)90201-8. URL http://www.sciencedirect.com/science/article/pii/0960852492902018.

B. Adams, L. Bauman, W. Bohnhoff, K. Dalbey, M. Ebeida, J. Eddy, M. Eldred, and P. Hough. Dakota, A Multilevel Parallel Object-Oriented Framework for Design Optimization, Parameter Estimation, Uncertainty Quantification, and Sensitivity Analysis: Version 6.0 User's Manual. Sandia Technical Report SAND2014-4633, 2014.

S. Alok and G. Immanuel. Effect of Different Impellers and Baffles on Aerobic Stirred Tank Fermenter Using Computational Fluid Dynamics. Journal of Bioprocessing \&3 Biotechniques, 4(7):1, 2014.

J. L. Ansoni and P. Seleghim. Optimal Industrial Reactor Design: Development of a Multiobjective Optimization Method Based on a Posteriori Performance Parameters Calculated from CFD Flow Solutions. Advances in Engineering Software, 91:23-35, 2016.

J. Aubin, D. F. Fletcher, and C. Xuereb. Modeling Turbulent Flow in Stirred Tanks with CFD: The Influence of the Modeling Approach, Turbulence Model and Numerical Scheme. Experimental thermal and fluid science, 28 (5):431-445, 2004.

D. Bertsimas, D. B. Brown, and C. Caramanis. Theory and Applications of Robust Optimization. SIAM Rev., 53(3): 464-501, Aug. 2011. ISSN 0036-1445. doi: 10.1137/080734510. URL http://dx.doi.org/10.1137/080734510.

J. Blazek. Computational Fluid Dynamics: Principles and Applications. Elsevier, 2nd edition, 2004.

F. Börner and J. Börner. Doppelschneckenextruder und Verfahren zum thermomechanischen Aufschluss von organischen Roh- und Reststoffen, Oct. 5 2011. URL http://www.google.com/patents/EP2371525A2?cl=de. EP Patent App. EP20,110,160,242. 
D. Dapelo and J. Bridgeman. Assessment of Mixing Quality in Full-scale, Biogas-mixed Anaerobic Digestion Using cfd. Bioresource Technology, 265:480 - 489, 2018. ISSN 0960-8524. doi: https://doi.org/10.1016/j.biortech.2018. 06.036. URL http://www.sciencedirect.com/science/article/pii/S0960852418308150.

R. D. Donno, S. Rebay, and A. Ghidoni. Surrogate-Based Shape Optimization of the ERCOFTAC Centrifugal Pump Impeller. Springer International Publishing, 2019. Chapter in Evolutionary and Deterministic Methods for Design Optimization and Control With Applications to Industrial and Societal Problems.

D. Finkel and C. Kelley. Convergence Analysis of the DIRECT Algorithm. Technical report, North Carolina State University, Center for Research in Scientific Computation, Raleigh, 2004.

B. L. Gorissen, hsan Yankolu, and D. den Hertog. A Practical Guide to Robust Optimization. Omega, 53:124 - 137, 2015. ISSN 0305-0483. doi: https://doi.org/10.1016/j.omega.2014.12.006. URL http://www.sciencedirect. com/science/article/pii/S0305048314001698.

W. Gujer and A. J. B. Zehnder. Conversion Processes in Anaerobic Digestion. Water Science and Technology, 15 (8-9):127-167, 08 1983. ISSN 0273-1223. doi: 10.2166/wst.1983.0164. URL https://doi.org/10.2166/wst. 1983.0164.

Z. Guo, L. Song, Z. Zhou, J. Li, and Z. Feng. Multi-Objective Aerodynamic Optimization Design and Data Mining of a High Pressure Ratio Centrifugal Impeller. Journal of Engineering for Gas Turbines and Power, 137:092602, 09 2015. doi: 10.1115/1.4029882.

D. Jones, C. Perttunen, and B. Stuckman. Lipschitzian Optimization Without the Lipschitz Constant. Journal of Optimization Theory and Application, 79:157-181, 1993.

F. Kemausuor, M. Adaramola, and J. Morken. A Review of Commercial Biogas Systems and Lessons for Africa. Energies, 11(11):2984, Nov 2018. ISSN 1996-1073. doi: 10.3390/en11112984. URL http://dx.doi.org/10. $3390 /$ en11112984.

M. Kraume. Transportvorgänge in der Verfahrenstechnik: Grundlagen und apparative Umsetzungen. SpringerVerlag, 2013.

H. Landry, C. Gue, and M. Berge. Physical and Rheological Properties of Manure Products. Applied engineering in agriculture, 20(3):277-288, 2004.

F. Menter, M. Kuntz, and R. Langtry. Ten Years of Industrial Experience with the SST Turbulence Model. Turbulence Heat and Mass Transfer, 4:625-632, 2003.

R. N. Meroney and R. E. Sheker. CFD Simulation of Vertical Linear Motion Mixing in Anaerobic Digester Tanks. Water Environment Research, 86(9):816-827, 2014. 
J. Müller. Mathematische Modelle zur Optimierung mechanisch induzierter Mischprozesse. PhD thesis, Technische Universität Berlin, 2019.

D. Pasquale, A. Ghidoni, and S. Rebay. Shape Optimization of an Organic Rankine Cycle Radial Turbine Nozzle. Journal of Engineering for Gas Turbines and Power, 135:042308, 04 2013. doi: 10.1115/1.4023118.

A. Ribes and C. Caremoli. Salome Platform Component Model for Numerical Simulation. In Computer Software and Applications Conference, 200\%. COMPSAC 200\%. 31st Annual International, volume 2, pages 553-564. IEEE, 2007.

C. Sadino-Riquelme, R. E. Hayes, D. Jeison, and A. Donoso-Bravo. Computational Fluid Dynamic (cfd) Modelling in Anaerobic Digestion: General Application and Recent Advances. Critical Reviews in Environmental Science and Technology, 48(1):39-76, 2018. doi: 10.1080/10643389.2018.1440853. URL https://doi.org/10.1080/ 10643389.2018 .1440853$.

J. L. Sawin, F. Sverrisson, W. Rickerson, C. Lins, L. E. Williamson, R. Adib, H. E. Murdock, E. Musolino, M. Hullin, A. Reith, et al. Renewables 2015 Global Status Report-Annual Reporting on Renewables: Ten Years of Excellence. Water Environment Research, 2015.

A. Stirl. Biogasfermenter mit separatem Rührwerk, Dec. 4 2008. URL http://google.com/patents/ DE102007024947A1?cl=ja. DE Patent App. DE200,710,024,947.

S. Theuerl, C. Herrmann, M. Heiermann, P. Grundmann, N. Landwehr, U. Kreidenweis, and A. Prochnow. The Future Agricultural Biogas Plant in Germany: A Vision. Energies, 12(3):396, Jan 2019. ISSN 1996-1073. doi: 10.3390/en12030396. URL http://dx.doi.org/10.3390/en12030396.

B.-H. Um and T. R. Hanley. A Comparison of Simple Rheological Parameters and Simulation Data for Zymomonas Mobilis Fermentation Broths with High Substrate Loading in a 3-l Bioreactor. Applied Biochemistry and Biotechnology, 145(1-3):29-38, 2008.

Umweltbundesamt. Erneuerbare Energien in Deutschland Daten zur Entwicklung im Jahr 2016, February 2017.

URL https://www.umweltbundesamt.de/sites/default/files/medien/376/publikationen/erneuerbare_ energien_in_deutschland_daten_zur_entwicklung_im_jahr_2016.pdf.

M. S. Vesvikar and M. Al-Dahhan. Flow Pattern Visualization in a Mimic Anaerobic Digester Using CFD. Biotechnology and Bioengineering, 89(6):719-732, 2005.

P. Weiland. Biogas Production: Current State and Perspectives. Applied Microbiology and Biotechnology, 85(4): 849-860, 2010.

H. G. Weller, G. Tabor, H. Jasak, and C. Fureby. A Tensorial Approach to Computational Continuum Mechanics Using Object-Oriented Techniques. Computers in Physics, 12(6):620-631, 1998. 
B. Wu and S. Chen. CFD Simulation of Non-Newtonian Fluid Flow in Anaerobic Digesters. Biotechnology and Bioengineering, 99(3):700-711, 2008. 